\title{
Simona-Nicoleta VULPE*
}

\section{To Vaccinate or Not to Vaccinate against HPV? A Content Analysis of Vocabularies of Motives}

\begin{abstract}
In the present paper, I conducted a comparative study of vocabularies of motives that Romanian and American parents employ in the online environment on the topic of HPV vaccination. I started from C. W. Mills's (1940) article on vocabularies of motives, integrating into my analysis the concepts of filter bubbles and echo chambers. The research method that I employed is the content analysis of posts and comments from Facebook pages dedicated to the topic of vaccination. My results show that the vocabularies of Romanian and American parents are similar. In confrontational interactions on anti-vaccination pages the vocabularies of motives mirror each other, being centered on the adverse effects of the HPV vaccine and the dangers of not vaccinating. In consensual interactions on anti-vaccination pages, mandatory vaccination is advanced as the core motive within a flourishing vocabulary. On pro-vaccination pages, confrontational interactions give rise to vocabularies of motives concentrated on risks and dangers and also on accusations against anti-vaccination supporters. Consensual interactions on these pages generate circular vocabularies formed of accusations against anti-vaccinators and the reiteration of the danger of not vaccinating. Beyond the striking opposition between pro- and anti-vaxxers, there are intra-categorical discrepancies accompanied by mixt vocabularies of motives.
\end{abstract}

Keywords: HPV vaccination, vocabularies of motives, anti-vaccination, pro-vaccination, Facebook pages.

\section{Introduction}

Human Papilloma Virus (HPV) is the most common sexually transmitted infection (Perez et al., 2015, p. 1316). In Romania, over 8 million women are at risk of developing cervical cancer (Bruni et al., 2018). Almost 2000 women die of cervical cancer annually, the highest rate in the European Union (Merck Sharp \& Dohme România, 2018). In the USA, there are 44.000 cases of cancers associated with HPV infections every year (Centers for Disease Control and Prevention, 2019). Within the population, female patients most frequently suffer from cervical cancer, whereas male patients are mostly affected by oropharyngeal forms of HPV cancer. The vaccination coverage for the first dose of the HPV vaccine is of $69 \%$ for adoles-

* University of Bucharest, Romania, mona.vulpe@gmail.com 
cent girls and $63 \%$ for adolescent boys. Vaccination programs are funded by private and public sources in order to assure the vaccination coverage for US children and young adults (The Kaiser Family Foundation, 2018) .

There have been no recent campaigns in Romania advocating for HPV vaccination (the vaccine is not mandatory and it was not purchased by the Ministry of Health). There are no recent studies on this topic, either. The latest research on HPV vaccination in Romania comes from 2016 and it approaches the vaccination campaign from 2008. Under these circumstances, the study of decisions on HPV vaccination and the vocabularies of motives people employ on this topic is relevant for assessing the transformations that may have occurred in the Romanian society and for Romanian parents in regard to the HPV vaccination.

Vaccination, as a medical practice, is related to people's experience with the medical system and to their interaction with health care professionals, contributing to the acceptance or rejection of vaccination (Donovan \& Bedford, 2013). Mothers' decisions concerning children's health care are highly influenced by the attitude of health care professionals towards them (Gross \& Howard, 2001, p. 166). Furthermore, health care provider's recommendation to vaccinate the child/adolescent is of highly importance for parents' decision-making process (Sturm, Mays \& Zimet, 2005; Gilkey et al., 2017).

Some of the parents in UK who have been exposed to alternative medicine express their concern regarding the pharmaceutical industry and its connection with vaccination programs (Poltorak et al., 2005). Similar considerations were signaled in Romania, when analyzing people's preference for homeopathy over biomedicine (Rughini?, Ciocănel \& Vasile, 2017). Pharmaceutical companies engender concerns among people with regard to their interferences within both medical and political systems. The perceived corruption affecting these systems, particularly their exponents - doctors and politicians, fuels vaccine hesitancy. In addition, politicians are discredited as a result of legislative projects in favor of mandatory vaccination. Other motives invoked by the US population for vaccine rejection are related to religious or philosophical beliefs (Sturm, Mays \& Zimet, 2005; Tangherlini et al., 2016). In the United States, one of the recurrent factors influencing mothers' HPV vaccination decision of their daughters is mothers' history of STIs (Davis et al., 2004; Mays, Sturm \& Zimet, 2004; Zimet et al., 2005; Dempsey et al., 2006; Tiro et al., 2007). Parents are more likely to vaccinate their children if they perceive vaccines as being beneficial to society, to their own child, or if they were influenced by peer groups or by physicians to accept vaccination (Gamble et al., 2010; Staras et al., 2014).

The vaccination motives discussed above reflect rather the psychological use of the motive concept, whereas the sociological perspective stresses the social production of motives during interactions. When parents discuss their vaccination decisions, they present an argumentation based on vocabularies of motives that emphasize their position. Vocabularies of motives are usually employed when individuals' actions are questioned, such as when anti-vaccinators are accused of endangering their children. Defending one's position implies the reiteration of motive vocabularies, as mentioned by Wright Mills (1940).

This is a comparative research on the topic of HPV vaccination decisions in Romania and U.S.A. Based on previous research results (Vulpe \& Stoian, 2018) and on exploratory observations, I noticed that Romanian users of anti-vaccination Facebook pages provide links to anti-vaccination content published on US Facebook pages and websites. The objective of this research is to assess the vocabularies of motives that people employ for justifying their de- 
cisions on HPV vaccination in online interactions on Facebook. The research questions that I address are:

1. What are the vocabularies of motives that Romanian and American parents employ for justifying their decisions on HPV vaccination?

2. What are the main differences and similarities in the vocabularies used in the two countries?

\subsection{The interplay of vaccine hesitancy and vocabularies of motives}

Wright Mills's (1940) theory of vocabularies of motives was employed in order to study the HPV vaccination decisions of Romanian and American parents in the digital environment. Making use of filter bubbles and echo chambers concepts, I explain the proliferation of vaccine hesitancy among parents who use Facebook pages in order to discuss vaccination decisions. Digital networks allow for technologically mediated interactions in which parents statuses shift from one virtual interaction to another, as they move from discussions with people who share their views on vaccination to discussions with people who dismiss their position.

For psychologists, motives are split into two categories - primary and secondary motives. Individuals are born with primary motives, similarly to animals, but they learn secondary motives, which means the latter differ from one individual to another (Petri \& Cofer, 2018). In sociology, the concept of vocabularies of motives was coined by Wright Mills (1940) in what he referred to as motive vocabularies. In Wright Mills's conceptualization, vocabularies of motives were associated with social positions (Campbell, 1991, p. 89). Social actors present their motives when their actions are questioned by others (Wright Mills, 1940, p. 905). The author emphazised the social situatedness of motive vocabularies, which places them as essential for social roles. People learn vocabularies of motives just as they learn social norms and values (Wright Mills, 1940, p. 906).

However, in secular societies there are competing vocabularies of motives that operate at the same time and their appropriatness for a certain situation is not clearly articulated (Wright Mills, 1940, p. 911). Therefore, people adopt a certain conduct and accompany it with vocabularies of motives as a response to a situation in which they find themselves ( Wright Mills, 1940, p. 906). Persistence or abandon of a social conduct and/or motive vocabulary depends on the agreement of others.

People who reject the HPV vaccination are part of a network that involves both online and off-line ties. Individuals who are part of such networks share opinions and generate vocabularies of motives during interactions. Sometimes, they get in touch with supporters of vaccination who justify their position by employing a competing vocabulary. In response, the anti-vaccination party reiterates its vocabulary of motives trying to dislocate the competing one. When revealing their vocabularies of motives, people try to exercise influence on others, but also on themselves, as Wright Mills noticed (p. 907).

Beyond explaining how people present their motives depending on the social context, vocabularies of motives also reveal how knowledge is socially organized and how individuals make use of it, either complying with the existing social order or trying to induce change (Fitzgerald, 2013). Vaccination decisions are influenced by various sources of knowledge recognized as legitimate by parents. Nowadays, the legitimacy and authority of science are questioned on the basis of postmodern reflexivity and relativity (Giddens, 1990; Beck, 1992), 
therefore the benefits of vaccination also become questionable. In addition, the lack of scientific culture in Romania (Vlăsceanu, Du?a \& Rughini?, 2010) also encourages vaccination hesitancy among Romanian parents.

Giddens's analysis of late modernity places an emphasis on "risk culture" and "healthism" (Giddens, 1991). People autonomously make decisions for themselves guided by the knowledge produced within the scientific community, even if sometimes they question this knowledge. They are aware of the risks involved in the daily life and some of them try to avoid the dangers encompassed in these risks by making "natural", healthy choices. This perspective on the causes of vaccine hesitancy stresses the trend of healthy lifestyle and the rejection of chemical/unnatural substances.

The concept of vaccine hesitancy has been approached in numerous studies throughout the years, but its meaning is still open to various interpretations (Dubé et al., 2013, p. 1764). The ambiguity of the concept of vaccine hesitancy is rooted in the theoretical background, which generated several definitions for this concept. Among the definitions proposed for the hesitancy phenomenon towards vaccination, there is the understanding as "organized, collective opposition, as opposed to individual refusal" (Hobson-West, 2007, p. 200). However, hesitancy to vaccination is also defined as "individual behavior influenced by a range of factors, such as knowledge or past experiences" (Dubé et al., 2013, p. 1763). Social and cultural factors affect decisions on vaccination. These factors range from previous experiences with the medical system to friends' and relatives' opinions, religious motives and so on (Wolfe, Sharp \& Lipsky, 2002; Zimmerman et al., 2005; Tangherlini et al., 2016). MacDonald (2015) describes vaccine hesitancy as contextual, dynamic in time and space and as being influenced by the vaccine under discussion.

Vaccine hesitancy can be assimilated to parents' lack of knowledge or consideration in regard to vaccination (Dubé et al., 2013, pp. 1764-1765). Parents may hesitate towards one vaccine and consent to others, "newer vaccines usually engendering more hesitancy" (Dubé et al., 2013, p. 1765). Social normativity also presses parents to be informed, to know all sides of the story and to question any adoption of a position in their postmodern quest for good parenting. Thus, vaccine hesitancy is understood in terms of "the moral imperative to become informed", while "some kind of empowerment, personal responsibility and participation are expressed in highly positive terms" (Hobson-West, 2007, p. 212).

\subsection{Vaccination within filter bubbles and echo chambers}

New technologies have a powerful role in shaping debates and coordinating users' discourse. The machine-learning techniques behind search engines, news aggregators, and social media work in such a way that they provide the user with a personalized content. However, there are criticisms targeting social media and one of the most prominent of these is its contribution in the creation of filter bubbles and echo chambers, so users get in touch with content that confirms their beliefs and isolate them from divergent points of view (Flaxman, Goel \& Rao, 2016; Difranzo \& Gloria-Garcia, 2017).

There is a sensitive difference between filter bubbles and echo chambers. Pariser (2011) defined the filter bubble as a form of technological mediation performed by algorithms. As a result of user's manifested preference for a certain type of sources, opinions that contradict user's beliefs are left out by technological means. Echo chambers are similar to filter bubbles to the extent that they lack alternative opinions, but the process through which each of 
these structures achieves isolation is different. In echo chambers, alternative world views are deliberately excluded. In filter bubbles, the lack of alternative information is rather an accidental result of both users' initial choices and algorithm's selections. Users in echo chambers distrust sources outside their network because the respective sources have been discredited. Users in filter bubbles can escape this epistemic structure after being exposed to an alternative source, whereas echo chambers are reinforced by such a source (Nguyen, 2018).

Zuiderveen Borgesius et al. (2016) note that there are distinct mechanisms behind the confirmation bias in filter bubbles and echo chambers. Selective exposure, manifested as looking for and selecting confirmatory information is pervasive across filter bubbles, whereas selective avoidance, which consists of avoiding conflicting information, is often found in echo chambers (Nguyen, 2018). Rejection of what appears to be clear evidence is a commonly encountered behavior in some online networks, such as climate change deniers or antivaccination supporters. This aspect can be theoretically addressed by employing the echo chamber concept (Nguyen, 2018, p. 4). Echo chambers disrupt knowledge on causation by stimulating "speculation, rumors, and mistrust" (Del Vicario et al., 2016, p. 554).

\subsection{Prior research on HPV vaccination}

Parents' experiences and their demographic characteristics are among the predictors involved in their decisions to accept or to oppose vaccination, according to a systematic review published by Trim et al. (2012). Among the reasons vehiculated in the US literature for low rates of vaccination, there are precarious knowledge on HPV and HPV vaccination, the cost of the vaccine, and its efficacy (Allen et al., 2010). Factors involved in accepting the HPV vaccination are parents' perception of their children as being at risk to HPV infection, their perception of HPV infection severity, parents perceiving vaccines as dangerous, and concerns of HPV vaccine's effect on involvement in risky sexual behavior, as well as promiscuity (Constantine \& Jerman, 2007, p. 109).

Vaccination decisions and vocabularies of motives on this topic are also influenced by gender beliefs and by a gender dimension of health responsibility. A gender-neutral campaign for HPV vaccination is more effective in terms of prevention of genital warts and HPV-related cancers (Zimet \& Rosenthal, 2010). Vaccination policies addressing only girls are characterized as "perpetuating gender role stereotypes, reinforcing the idea that STDs are a women's issue", and a "failure to genuinely engage boys in this program is a missed opportunity to address gender equity" (Rae \& Kerridge, 2011 cited in Todorova \& Băban, 2012, p. 17). However, there are Romanian mothers who opt for vaccinating their sons as a form of shared responsibility, in order to protect girls, even if they do not perceive HPV as a potential cancer threat to their boys (Todorova \& Băban, 2012, pp. 17-18).

The gender of the child is also relevant for how parents talk about the risks of the HPV vaccine. Parents' concern that the HPV vaccine would encourage teenagers to get involved in sexual activity has been signaled in multiple US studies on this topic: Dailard, 2006; Constantine \& Jerman, 2007; Allen et al., 2010; Trim et al., 2012. Rejection motives based on sexual promiscuity were often found among U.S. parents who held conservative and religious beliefs. Their main fears target "sexual disinhibition and loss of parental rights to choose" (Casper \& Carpenter, 2008 cited in Todorova \& Băban, 2012, p. 19). Romanian parents on discussion forums analyzed by Pen?a and Băban (2014) motivated their rejection of HPV vaccine on the basis of vaccine's promotion of promiscuity (p. 20). The moral aspect was fre- 
quently stressed by users on these forums, with references to the HPV vaccine as altering girls' morality (p. 24). The morals and sexuality issues are probably specifically related to the HPV vaccine, given its connection with sex health and sexual education topics. This is consistent with MacDonald's (2015) conceptualiztion of vaccine hesitancy (contextual, dynamic) and suggestes that the HPV vaccine encompases not only a particular repertoire in terms of motive vocabulary, but also the changes that occur within this repreroire over time.

The vocabularies of motives regarding the HPV vaccination reflect cross-cultural differences. "Constructions are varied, local and historical", as Todorova and Băban (2012) note when examining parents' vaccination behavior (pp. 8-9). According to Lenselink et al., (2008), Dutch parents are not concerned of HPV vaccine' effects on children's sexual behavior, in contrast to the results of most American surveys. However, vaccination decisions of American mothers in Rosenthal et al.'s study (2008) were not related to "their sexual values or to their daughters' sexual behavior, but rather to their parenting, sense of vulnerability, and vaccine attitudes" (p. 239). In Romania and Bulgaria parents were not particularly concerned of sexual disinhibition as a result of HPV vaccination, although promiscuity has been addressed in some discussion forums, as I previously mentioned in this section. Parents' concerns in these countries revolved around infertility caused by the HPV vaccination, which was perceived as something that destroys a girls' femininity and contributes to not being "a woman anymore", this state of affairs being evaluated as worse than getting cancer (Todorova \& Băban, 2012, pp. 19-20).

The difference in perceived potential threats between countries like USA and UK, where the main HPV-related concerns revolved around little girls starting their sex life earlier, and countries like Romania and Bulgaria, where the main concern was girls' eventual incapacity to have children, portrays the difference in social expectations regarding liberty/freedom, on the one hand, and duty, on the other (Pop, 2016). In Eastern Europe, in general, and in Romania, in particular, the HPV vaccination is related to "historical legacies around fear, mistrust, blame and responsibility" (Todorova \& Băban, 2012, p. 24). The particularities of Romanian attitudes and vocabularies of motives in regard to the HPV vaccine consist of the legacy of communist repressive measures with regard to the "reproductive and sexual behavior", along with "monitoring and suppression of reproductive rights" (Băban, 1999 cited in Todorova \& Băban, 2012, p. 24).

Moreover, parents tend to perceive the HPV vaccine similarly to the contraceptive pill and employ the same vocabulary of motives when accounting for their decisions. Parents consider the vaccine to be necessary for their children only when they become sexually active (Trim et al., 2012). Similar considerations were found by Gilkey et al. (2017) among US parents. The perceived disinhibition promoted by the HPV vaccine is frequently encountered among religious and conservative parents, who also dismiss vaccine's efficiency regarding STDs protection (Todorova, Alexandrova-Karamanova \& Dimitrova, 2012). Social-environmental factors were identified by Sturm, Mays and Zimet (2005) as central for parental decision to immunize children and adolescents. Parents who are part of anti-vaccination groups, alternative parenting, or have a religious denomination that opposes vaccines are pressured to conform to social group norms that reject vaccination (p. 442). In addition, these parents are also pressured to employ a vocabulary of motives for vaccine hesitancy that is pervasive across the group they are part of.

Parents often turn to online forums and websites to address their questions and concerns on health issues, including those related to vaccination. Tangherlini et al. (2016) studied two 
parenting websites that provided the users with a safe space where they could share their strategies on how to avoid vaccination. Therefore, these strategies become a part of parents' vocabularies of motives in this particular digital environment. Parents also evoke in their online community adverse effects of vaccines, insisting on "autism, pain, compromised immunity, and even death". Zimmerman et al. (2005) studied anti-vaccination websites and found that people participating in online discussions placed responsible parenting at the center of vaccine rejection. Participants defined responsible parenting as protecting one's child by distrusting the medical system and preferring alternative medicine instead. Some of the participants in the study conducted by Sturm, Mays and Zimet (2005) considered that being a responsible parent requires challenging/questioning medical practices and recommendations, while others defined parental responsibility in terms of conforming to health professionals' suggestions (p. 449).

Parental consent is rather new for Romanian parents, who were used to compulsory vaccination during the communist regime. The vaccination consent they have to give is interpreted as a lack of responsibility within the medical system and as a transfer of responsibility to parents (Crăciun \& Băban, 2012, p. 6791), which could threaten their good parent status. When interviewing English parents, Poltorak et al. (2005) observed that their discussions on vaccination revealed narratives that exposed a valued parenthood and how they approached their responsibility to their children (p. 718). American mothers from rural areas reported as very important to them "to be thought of as good mothers", when questioned about their decisions regarding children's health care (Gross \& Howard, 2001, p 167). Therefore, maintaining the status of good parent requires a particular behavior in regard to health care and also a vocabulary of motives to account for the respective behavior.

\section{Methodology}

As documented in previous research, parents decide whether to vaccinate their children against HPV based on several motives, which they advance in order to reiterate their vaccination position. However, the studies presented in the previous section do not account for the social situatedness of vaccination motives. Being interested in vocabularies of motives as products of social interactions, I aim to answer the following research questions:

1. What are the vocabularies of motives that Romanian and American parents employ for justifying their decisions on HPV vaccination?

2. What are the main differences and similarities in the vocabularies used in the two countries?

A qualitative approach was employed for this study in order to capture the interpretative elements of parents' vocabularies of motives for HPV vaccination and the negotiations they get involved in for defining their vaccination position. Using the content analysis as research method, I explored parents' discussions of HPV vaccination in the online environment in order to gain an in-depth perspective of vaccination decisions and the vocabularies of motives they employ in various interactional situations.

Not only parents are involved in these discussions. People who do not have children also participate and discuss vaccination as an experience affecting their own body/health. Since 
vocabularies of motives circulate across social groups, they are specific not only to a single social category, but to various groups.

Posts and comments from Romanian and US Facebook pages dedicated to pro- and antivaccination issues were studied in order to analyze and compare the vocabularies of motives. I selected two anti-vaccination pages and the profile of a prominent anti-vaccination supporter, along with two pro-vaccination pages and the profile of a prominent pro-vaccination supporter for each of the countries included in the analysis. The anti-vaccination Facebook pages from Romania are: Vaccinuri - Cite?te Prospectele, NOI NU vaccinăm, and the FB account of Feli Popescu. The pro-vaccination Facebook pages from Romania are: Coali?ia România Sănătoasă, Vaccinuri ?i vaccinare, and the FB account of Ovidiu Covaciu. The anti-vaccination Facebook pages from U.S.A. are: Corrupt Vaccines, Texans for Vaccine Choice, and the FB account of Jenny McCarthy. The American pro-vaccination pages in my study are: Voices for Vaccines, Refutations to Anti-Vaccine Memes, and the FB account of Bill Gates.

I searched for these pages on Facebook using the following keywords: vaccine, vaccination, anti-vaccination, pro-vaccination. The pages for the analysis were selected based on the number of followers (see Table 1), the criterion for selection being the high popularity of the page. Taking into account the number of followers, the discourse created on these pages spreads fast and can influence a large number of people who are active on this social network. The pro- and anti-vaccination supporters were identified using references in posts and comments on the Facebook pages that I previously mentioned. With regard to Romanian antivaccination supporters, Olivia Steer is more famous than Feli Popescu. However, Olivia Steer's Facebook page was not available during data collection, following her controversial participation in a TV debate on vaccination.

Table 1. Information on the Facebook pages included in the analysis

\begin{tabular}{|l|l|c|c|}
\hline \multicolumn{1}{|c|}{ Facebook page } & Position towards vaccination & Country & No. of followers \\
\hline NOI NU vaccinăm & Anti-vaccination & Romania & 13.013 \\
\hline Vaccinuri - Citește Prospectele & Anti-vaccination & Romania & 7.036 \\
\hline Feli Popescu & Anti-vaccination & Romania & 3.864 \\
\hline Coalitia România Sănătoasă & Pro-vaccination & Romania & 24.302 \\
\hline Vaccinuri și vaccinare & Pro-vaccination & Romania & 1.138 \\
\hline Ovidiu Covaciu & Pro-vaccination & Romania & 1.178 \\
\hline Texans for Vaccine Choice & Anti-vaccination & U.S.A. & 22.539 \\
\hline Corrupt Vaccines & Anti-vaccination & U.S.A. & 20.887 \\
\hline Jenny McCarthy & Anti-vaccination & U.S.A. & 1.065 .356 \\
\hline Refutations to Anti-Vaccine Memes & Pro-vaccination & U.S.A. & 268.773 \\
\hline Voices for Vaccines & Pro-vaccination & U.S.A. & 18.571 \\
\hline Bill Gates & Pro-vaccination & U.S.A. & 19.569 .915 \\
\hline
\end{tabular}

I used the search option in order to identify on these pages the posts and comments related to the HPV vaccination from 2018. After selecting the posts for my study, I proceeded to analyze their content using deductive content analysis, starting from existing theory and aim- 
ing to make comparisons with previous research results (Elo and Kyngäs, 2008). The unit of analysis for my research was the paragraph.

According to previous research results, parents discuss vaccination as related to adverse effects of vaccines, benefits of vaccination, doctors and medicine, or as being influenced by religious aspects. I started to process the data by assessing the type of online interaction. There are three main social situations in which Facebook users interact in regard to the HPV vaccination. More specifically, the interactional situations involve pro-vaccination supporters, anti-vaccination supporters, or pro- and anti-vaccination supporters. As I inspected the data, I coded paragraphs of posts and comments (the short comments - one phrase - were considered a unit of analysis in themselves) according to patters of discussion that guided me to generate narrow categories of motives. As a next step, I collapsed the narrow categories into broad categories of motives, the latter being presented in the following analysis scheme (Table 2):

Table 2. Analysis scheme

\begin{tabular}{|c|c|c|}
\hline Category & Definition & Examples \\
\hline $\begin{array}{l}\text { Pro-vax inter-parental interaction } \\
\text { - References to risks and dangers } \\
\text { - References to the medical system } \\
\text { - References to the political system } \\
\text { - References to religion } \\
\text { - Type of argument } \\
\text { - User's gender } \\
\text { - Other reporting frameworks }\end{array}$ & $\begin{array}{l}\text { Discussions } \\
\text { between pro- } \\
\text { vaccination parents }\end{array}$ & $\begin{array}{l}\text { "She has a daughter and she does not } \\
\text { want to vaccinate her against HPV. } \\
\text { Because it is pleasant to have cancer and } \\
\text { to die because of it"; "How is that, } \\
\text { Ovidiu??? God forbid...I had } 2 \text { cases close } \\
\text { to me. It is terrible. It is awful." }\end{array}$ \\
\hline $\begin{aligned} & \text { Anti-vax inter-parental interaction } \\
& \text { - References to risks and dangers } \\
& \text { - References to the medical system } \\
& \text { - References to the political system } \\
& \text { - References to religion } \\
& \text { - Type of argument } \\
& \text { - User's gender } \\
& \text { - Other reporting frameworks }\end{aligned}$ & $\begin{array}{l}\text { Discussions } \\
\text { between anti- } \\
\text { vaccination parents }\end{array}$ & $\begin{array}{l}\text { "Looks like Sarah Davis is the Richard Pan } \\
\text { of Texas. Big Pharma found their useful } \\
\text { idiot in order to get Texas to follow } \\
\text { California's lead. CA already allows } 12 \\
\text { year-olds to consent to the HPV vaccine } \\
\text { without parental knowledge or permission. } \\
\text { Bad idea."; "Population control sounds like } \\
\text { to me." }\end{array}$ \\
\hline $\begin{array}{l}\text { Pro vs. Anti-vax inter-parental } \\
\quad \text { interaction } \\
\text { - References to risks and dangers } \\
\text { - References to the medical system } \\
\text { - References to the political system } \\
\text { - References to religion } \\
\text { - Type of argument } \\
\text { - User's gender } \\
\text { - Other reporting frameworks }\end{array}$ & $\begin{array}{l}\text { Discussions } \\
\text { between pro- and } \\
\text { anti-vaccination } \\
\text { parents }\end{array}$ & $\begin{array}{l}\text { "Excuuse me! But what does HPV cause? } \\
\text { Rather aggressive answers, Vaccinuri-.....! } \\
\text { Are you sure you don't have HPV?"; "It } \\
\text { causes the same thing as the vaccine." }\end{array}$ \\
\hline
\end{tabular}

The types of arguments that I identified in the data are: personal story, someone else's story, conspiracy theory, opinion, data/research, and supported by data/research. When coding user's gender, I used the code admin. for posts and comments written by the page administrator whose gender was not specified. In addition, I created the other reporting frameworks category in order to capture motives that do not fit into the rest of the categories. The categories comprised in the analysis scheme reflect several themes that organize the online discussion around topics related to parents' decisions on the HPV vaccination, as well as the vocabularies of motives they employ in order to justify their decisions. 


\section{Results}

The results of the content analysis conducted on Facebook pages illustrate motives as products of online interactions. The statuses of the users involved in the interaction, as well as the type of interaction - whether it is a confrontational situation or a consensual one shape the discourse and generate vocabularies of motives for vaccination decisions. Thus, vocabularies of motives have a contextual, interactional character.

When parents from adverse parties interact (pro- vs. anti-vaccination) their vocabularies of motives are centered on the adverse effects of the HPV vaccine and on the dangers of not vaccinating. When all the parents taking part in the online interaction have the anti-vaccination status, the vocabularies of motives are structured around mandatory vaccination as a harmful practice and around accusations against social actors supporting this practice (politicians, doctors, pro-vaccination parents). The vocabularies of motives constituted during the interactions between pro-vaccination parents are formed of accusations against anti-vaccinators and the dangers of not vaccinating.

The interactions between pro- and anti-vaccination parents from Romanian anti-vaccination Facebook pages generate vocabularies of motives structured around risks and dangers associated to vaccination. Anti-vaccination parents advance cancer as an adverse effect of the vaccine, whereas the pro-vaccination parents argue that cancer is a danger of the non-vaccination decision. The two vocabularies intersect at this point, when the users try to cancel out the competing vocabulary. The assertion of one motive - women die of cervical cancer - is followed by its negation as an adverse motive - the HPV vaccine provokes cancer (see the box below).

\section{Example 1}

"But how many women die because of the virus, you do not care about this!?! Stop intoxicating people with such things!" vs. "The vaccine provokes cancer, too, madam!"

The confrontation is between opinions, as type of arguments. The users also employ information supported by data/research, but more rarely than opinions. Only women participate in the pro- vs. anti-vaccination discussions. The vocabulary is compact, being focused on deconstructing/invalidating the previous adverse motive.

Anti-vaccination parents from Romanian anti-vaccination Facebook pages interact using more varied types of arguments than in the previous interactional situation. Opinions are the most frequent type of arguments used, but there are also (supported by) data/research arguments, stories (personal and someone else's), and conspiracy theories (mostly related to population control), although the latter are the least frequent. Mostly female users are involved in these interactions, but there is also one man involved. Motives are introduced as the interaction goes on: risks as adverse effects (neurologic diseases, epilepsy, or infertility), mandatory vaccination as a political matter, and the corruption of the medical system are advanced as motives accounting for rejection of HPV vaccination. The assertion that vaccination is a crime is linked to the religious dimension of the vocabulary - the invocation of God as a means of protection against vaccination. 


\section{Example 2}

"Morons who agree their children to get it, criminals those who produce it and those who administrate it. For girls too, not only for boys." "God forbid and protect!"

Furthermore, the rejection of gender-neutral vaccination campaigns is reinforced. Overall, the vocabulary is strengthened by progressively introducing motives against vaccination. Each new introduced motive validates the previous one and invites the next one. The interaction generates more and more motives, each new asserted motive producing others in line with it and nuancing the vocabulary. The vocabulary is not circular, as in the first interactional situation, but it is flourishing.

The interactional confrontations of parents on pro-vaccination Facebook pages from Romania mainly discuss mandatory vaccination as a political practice which introduces risks and dangers for children. Pro-vaccination parents make use of accusations against anti-vaccination parents (being ignorant, uneducated, incoherent) as an additional motive. In this case, the vocabularies are rather circular, although there is a slight expansion of the vocabulary as a product of previous interactions (discussions on mandatory vaccination later introduce risks and dangers as another category of motives). Besides the reduced variance in regard to the categories of motives, the same type of argument is largely employed - opinions. The majority of users are women, only one man was identified as taking part in the interaction.

Pro-vaccination parents from Romanian pro-vaccination Facebook pages are more often women, although there are significantly more men involved in these interactions compared to the situations that I presented above. During these interactions, parents employ the valorization of medicine as science, which fuels trust in doctors and vaccines as another motive in their vocabulary. Cancer is presented as the danger of not vaccinating and is reinforced repeatedly over interactions. They also accuse and insult anti-vaccination parents when accounting for their pro-vaccination decision. The vocabulary is compact and its expansion is limited, being concentrated around two reference categories (references to medical system and risks and dangers). The arguments are supported by data/research, but pro-vaccination parents frequently express their opinions, too.

The interactions between pro- and anti-vaccination parents on anti-vaccination Facebook pages from the USA give rise to adult vaccination as a new category of the anti-vaccination motive vocabulary. The adult vaccination motive implies that the HPV vaccine is problematic not only for children, but also for the adults who get vaccinated. The risks and dangers associated to the HPV vaccination are dominant within the vocabularies of motives. The refutation of the dangers of not vaccinating previously asserted generates an emphasis put on the respective dangers and the same dynamic occurs in regard to the adverse effects of the vaccine. Therefore, the vocabularies are concentrated, the interactions generating the refutation of the competing vocabulary. Some of the participants to the interactions are men. There are more supported by data/research arguments than opinions and there are no stories.

There are several men involved in the interactions between anti-vaccination supporters on anti-vaccination Facebook pages from the USA, although there are more women. Various types of arguments are employed, including conspiracy theories, which tend to appear less frequently in other interactions. The motives related to the risks of vaccination (death, infertility, or the simple statement of adverse effects) are followed by conspiracies of population control. References to the political system are expressed as the need for a more restrictive legislation in regard to the promotion of vaccines (especially to children). Derived from this, 
there is the responsibility motive - vaccination is parents' decision and therefore their responsibility (not children's responsibility or choice) and the consent motive (children are/should be legally unable to consent to vaccination). In addition, another motive related to the political system is the perceived similarity between mandatory vaccination and totalitarian regimes. Another dominant motive of this vocabulary is corruption (politicians and doctors are corrupted by Big Pharma). Among the motives that are less pervasive within the vocabulary, there is the intersection between religion and politics - parents' prayers to God for a legislation of no mandatory vaccination. On the whole, the vocabulary expands as more motives are brought up for discussion.

Pro- and anti-vaccination users of Facebook pages dedicated to pro-vaccination in the USA make reference to risks (adverse effects) and dangers (HPV cancers) when accounting for their vaccination decisions. They also employ motives related to the medical system when they evaluate the HPV vaccine as effective or ineffective, the effectiveness of the vaccine being accompanied by assertions of trust in the medical system. In regard to the anti-vaccination vocabulary, a motive that was not signaled in previous research is the stigmatization of the HPV vaccine because of to its connection to STDs.

\section{Example 3}

"No other cancer has to deal with the ridiculous stigma that because we didn't get a shot we are all going to have cancer. Why does cervical cancer not get the same attention as breast cancer. Why do we keep pushing the vaccine so hard and shaming people who have cervical cancer. But every other cancer it's oh fight for the cure. But cervical cancer gets hey ppl get the shot and then you won't get an std and die."

Users reject stories as unimportant and/or irrelevant information compared to data/statistics. Each of the parties employs motives trying to deconstruct the adverse vocabulary and, in the end, the competing vocabularies validate each other opositionally. The discourse is not expanding because of its circularity around a reduced number of themes and narrow vocabularies of motives. Only one man takes part in the online discussions.

On Facebook pages dedicated to pro-vaccination in the USA there are more women than men involved in pro-vaccination interactions, but the proportion of men is significantly higher compared to the previous situations. The danger of not vaccinating concretized as cancer is advanced as a motive for HPV vaccination. Some users present personal stories of minor adverse effects they experienced, such as burning of the vaccinated area, in an attempt to discredit the adverse effect (anti-vaccination) motive (although there are no anti-vaccination supporters to interact with). The expressions of trust in the medical system are accompanied by accusations against inefficient doctors and medical experts/authorities whose fault is the spread of the anti-vaccination movement.

\section{Example 4}

"How long did it take the lancet to fully retract the washed up fraud Wakefield's crackpot study down before it did the damage we see today?"

Moreover, the vocabulary of motives includes accusations against anti-vaccination supporters and against those who refuse vaccination and other medical procedures based on religious motives, although they are not participating in the interaction. 


\section{Example 5}

"Same hyper-religious belief that tubal ligation causes terrible periods. It's more like tubal ligation lets women get off the hormonal birth control which was disguising terrible periods. Nothing must stand in the way of the pro-life compulsory baby factory. Nothing!!!”

Anti-vaccinators are absent as an entity from these interactions, but their vocabulary of motives is still present, as a result of pro-vaccinators' evocations. Another motive for vaccinating is the refutation of promiscuity (although no one asserted promiscuity as an anti-vaccination motive in this interaction). The fact that children accept the HPV vaccine is part of the pro-vaccination vocabulary, as is the support for men who get the HPV vaccine. All types of arguments are employed.

Despite the pervasiveness of pro- and anti-vaccination orientations, there are also users who refuse to identify as such and employ mixt vocabularies of motives to account for their support of parents' freedom to choose whether to vaccinate their children. The mixt vocabularies can be found on both confrontational and consensual interactions. Even if these vocabularies are employed on pro- and anti-vaccination pages, they are more frequent on anti-vaccination ones. An example of mixt vocabulary can be found in Table 3.

Table 3. Types of vocabularies of motives

\begin{tabular}{|l|l|l|l|}
\hline $\begin{array}{l}\text { Facebook } \\
\text { page }\end{array}$ & $\begin{array}{l}\text { Interactional } \\
\text { situation }\end{array}$ & $\begin{array}{l}\text { Vocabulary } \\
\text { of motive }\end{array}$ & \multicolumn{1}{c|}{ Example } \\
\hline $\begin{array}{l}\text { Pro- } \\
\text { vaccination }\end{array}$ & $\begin{array}{l}\text { Confrontational } \\
\text { situation }\end{array}$ & $\begin{array}{l}\text { Concentrated } \\
\text { vocabulary }\end{array}$ & $\begin{array}{l}\text { "Just because you have the vaccine doesn't mean you } \\
\text { won't get hpv. It lowers the chance." Vs. "Yes, the same } \\
\text { way seat belts lower your chance of dying in a car } \\
\text { accident." }\end{array}$ \\
\hline $\begin{array}{l}\text { Anti- } \\
\text { vaccination }\end{array}$ & $\begin{array}{l}\text { Confrontational } \\
\text { situation }\end{array}$ & $\begin{array}{l}\text { Mirror } \\
\text { vocabulary }\end{array}$ & $\begin{array}{l}\text { "But how many women die because of the virus, you do not } \\
\text { care about this!?! Stop intoxicating people with such things!" } \\
\text { vs. "The vaccine provokes cancer, too, madam!" }\end{array}$ \\
\hline $\begin{array}{l}\text { Pro- } \\
\text { vaccination }\end{array}$ & $\begin{array}{l}\text { Consensual } \\
\text { situation }\end{array}$ & $\begin{array}{l}\text { Circular } \\
\text { vocabulary }\end{array}$ & $\begin{array}{l}\text { "'ve had discussions surrounding the HPV vaccine with } \\
\text { other people, and many have focused around the } \\
\text { "promiscuity" aspect, and none have even thought of the } \\
\text { fact that it's about preventing cancer. Both my son and } \\
\text { daughter will receive this vaccine when they're old } \\
\text { enough."; "I think that the struggle with that is that } \\
\text { someone's "husband" or "wife" could pass that on. It only } \\
\text { takes one partner. To claim promiscuity just puts people at } \\
\text { risk for a life threatening illness." }\end{array}$ \\
\hline $\begin{array}{l}\text { Anti- } \\
\text { vaccination }\end{array}$ & $\begin{array}{l}\text { Consensual } \\
\text { situation }\end{array}$ & $\begin{array}{l}\text { Flourishing } \\
\text { vocabulary }\end{array}$ & $\begin{array}{l}\text { "They have mandatory vaccines in NY now... yikes! Thank } \\
\text { God for Texas and parents having more medical freedom."; } \\
\text { "And how many more vaccine injuries must we endure until } \\
\text { folks wake up? One size does NOT fit all." }\end{array}$ \\
\hline $\begin{array}{l}\text { Paccination } \\
\text { vanti }\end{array}$ & $\begin{array}{l}\text { Confrontational } \\
\text { and } \\
\text { consensual } \\
\text { situations }\end{array}$ & $\begin{array}{l}\text { Mixt } \\
\text { vocabulary }\end{array}$ & $\begin{array}{l}\text { "I vaccinated all three of my children (except for the HPV). I } \\
\text { had no problem doing so. I'm not an anti-vaxxer, I'm a } \\
\text { 'Parent's choice" person. So maybe they fail to see there } \\
\text { are more voices then they think..." }\end{array}$ \\
\hline
\end{tabular}




\section{Discussion and conclusions}

During their interactions on Facebook pages, parents generate motives for their HPV vaccination decisions. Such motives aggregate into vocabularies of motives which are employed in order to emphasize one's position and to destabilize the adverse vocabulary. The vocabularies are refined during interactions as a result of how people adapt them to specific interactional situations. The pro- and anti-vaccination discourses validate each other oppositionally. Some of the online interactions that I analyzed allow the emergence of flourishing vocabularies by continuously adding motives, while other interactions shape narrow vocabularies focused on the opposition between the two parties: pro- and anti-vaccination. Beyond this striking opposition, neither of parties is homogenous, as the vocabularies show intra-categorical discrepancies and nuances generated by the vaccination phenomenon. For example, there are people who support vaccination, but express worries about the effectiveness of the HPV vaccine as a motive for vaccine hesitancy. People who are assumed to be anti-vaccination clarify their status by saying they are pro-choice and do not entirely reject vaccination. Such presentations of status occur in particular interactions, mainly because they are brought about as vocabularies of motives collide or intersect.

The vocabularies of Romanian and American parents are similar. Since parents use online sources to document their vaccination position (illustrated by the sources they provide on Facebook pages), this suggests that they learn the vocabularies of motives as they get in touch with Facebook users from other countries (examples from the USA, UK, and Italy given by Romanian parents). Men get involved mostly in pro-vaccination discussions, when the interactional situation is consensual and not confrontational, all of the participants in interaction having the pro-vaxxer status. Some of the American men taking part in these interactions got vaccinated against HPV and support the gender-neutral campaign, a motive that spreads among the pro-vaccination participants and extends their vocabulary of motives.

For anti-vaxxers, the topic of adverse effects to the HPV vaccine is prioritized within the vocabulary of motive. Furthermore, the adverse effects presented by these parents are assimilated to the adverse effects of other vaccines and this happens for both Romanian and American parents. The discussions on infertility and sexual disinhibition are marginal. This result of my analysis shows the time dynamic of the vocabulary of motives in Romania and contrasts with previous research conducted on the vaccination campaign from 2008. During this campaign, anti-vaccination parents insisted on infertility as a particular adverse effect of the HPV vaccine (Todorova \& Băban, 2012; Crăciun \& Băban, 2012). In 2018, anti-vaccination parents indicate several adverse effects for the HPV vaccine (paralysis, epilepsy, infertility, cancer, death) and evaluate it as being equally harmful as other vaccines in terms of adverse effects.

Big Pharma is a prominent actor for anti-vaxxers and it is integrated within the medical and political system. Anti-vaccinators try to incriminate the medical system as dangerous for children's health because of vaccines' adverse effects and to discredit doctors' reputation of experts/professionals in the health domain. On the other hand, pro-vaxxers do not overtly rely on Big Pharma as an entity. They do not acknowledge its existence as an entity operating within the medical system (or the political system), although they use vaccines produced by pharmaceutical companies to fight diseases and acknowledge their effectiveness. The political system is contested by both parties, who assimilate it to politicians. In various social interactions, anti-vaccinators' vocabulary of motives is centered on risks and dangers - children's 
health is endangered by politicians' intentions to adopt mandatory vaccination, which will cause adverse effects to all children.

Mandatory vaccination, which could be imposed by the political system, is regarded as a potential threat by parents who reject vaccination, while some of the parents who accept vaccination dismiss this practice, too. A split among pro-vaccinators is marked by people who identify as pro-vaxxers, but oppose mandatory vaccination as a form of support for parents' right to choose. Mandatory vaccination gives rise to a set of conflicts because of its interference with issues such as responsibility for children's health and the authority to make decisions for children. Parents regard mandatory vaccination as depriving them of their parental role and stripping away one of the tools they use to acquire the good parent status documented in previous research (Gross \& Howard, 2001; Zimmerman et al., 2005; Sturm, Mays \& Zimet, 2005). This applies to people who accept vaccination, too, because in the absence of a pro-vaccination choice, they cannot perform the role of the parent who takes care of children's health, since this becomes a prerogative of the state/political system. In the USA, the parental role in regard to children's health is further challenged by legislative projects that would allow children to decide for themselves whether to get the HPV vaccine or not.

Technology creates a particular universe of ideas and decisions that are framed by vocabularies of motives. These vocabularies are employed in the online environment and give rise to a digital dynamic in online interactions that generate interactional structures combining both filter bubbles and echo chambers characteristics. Echo chambers discredit sources outside the network and this is practiced in both pro- and anti-vaccination networks. In contrast to echo chambers, there is a break in filter bubbles that allows contrary opinions to get to the users without being immediately dismissed. This explains the split within the broad pro- and anti-vaccination categories. This split generated mixed vocabularies as a result of the intersection of pro- and anti-vaccination motives. The most common example is the pro-choice supporter - people who accept vaccination opinions/motives that are contrary to their own and reject what they consider to be a potential censorship of them (mandatory vaccination). Although pro-choice supporters tend to be assimilated to anti-vaxxers, my analysis shows that there are multiple vocabularies accounting for vaccine choice and they are not only another variation of the anti-vaccination vocabulary. However, the mixt vocabularies are not able to take over the debate and thus remain fragmentary in relation to the pro- vs. anti-vaccination cleavage.

My research contributes to the theory of motive vocabulary, as motives employed in the online environment show distinct features compared to Wright Mills's (1940) theorization of motive vocabularies. Social positions are more fluid in the online environment than in offline interactions. Users navigate through pages/groups and their statuses can shift abruptly, from consensual interactions to confrontational ones, depending on other users' position and on the climate in the online medium. The fluidity encountered in the online enviroment is common in post-modern societies, as are the risks and the individual reflexivity enacted in order to manage risks and make decisions for oneself and for one's children.

Mills emphazised the social situatedness of motive vocabularies, but since motives are situated in this fluid environment, several dynamics of vocabularies emerge: concentrated, mirror, circular, flourishing, and mixt vocabularies of motives. There are no generic vocabularies of motives, as they are defined by social actions and thus support interactional situations. Persistence or abandon of a social conduct and/or motive vocabulary is influenced by the agreement of others. The mixt vocabularies on HPV vaccination allow people to gain a cer- 
tain level of agreement form both parties and thus to consolidate their status. This is also accompanied by a reduced need to defend the mixt position. Given that social actors present their motives mainly when their actions are questioned by others, the mixt position goes unquestioned, to some extent, on the basis of individual freedom and reflexivity, as it exerts congruence with some of the others' motives.

\section{Implications and limitations}

This research has implications for public health campaigns regarding the HPV vaccination. Understanding parents' motives for their rejection of HPV vaccination would help to eventually implement successful policies for preventing HPV-related cancers. Despite their current absence from the Romanian society, such policies have been successful in lowering HPV infection rates in other countries (Grandahl et al., 2014).

An effective vaccination campaign should take into account parents' vocabularies of motives for accepting/rejecting the HPV vaccination. It should also consider how parents respond to cues to vaccinate their children against HPV, based on the social situation created by the campaign (parents, as the audience, and the communicator - doctor, politician/minister of heath, pro-vaccination ordinary people etc.). This would allow for a well-thought message, adjusted to the vocabularies that circulate across society. Also, the initiator of the campaign should consider the fact that vocabularies circulate across societies, so some motives circulate trans-nationally. In order to adequately address the HPV vaccination concerns, politicians should not appear in such campaigns, since neither pro-vaxxers, nor anti-vaxxers show esteem for them. Supporters of vaccine choice should carry the message of the campaign, since they reach a certain level of agreement from both parties, so their position would be respected, at least to a certain extent. The HPV vaccination may be presented as parents' choice - the choice to vaccinate one's child is an opportunity to act as a good, responsible parent.

In terms of future research, the concept of vocabularies of motives could be applied to the study of other current controversies, such as climate change denial or legitimization of alternative medicine. Such controversies require accounting practices that individuals use in order to construct and sustain the legitimacy of their position. Therefore, a similar research approach would unveil the social situatedness of motives as essential pillars in the social construction of discourses.

This research delved into the qualitative aspects of HPV vaccination. Nonetheless, a quantitative approached could be implemented in future research in order to test some hypotheses derived from the results of this study. As a first step in a quantitative study, it should be assessed how many people actually know about the HPV vaccine (and the HPV virus). This information is of particular interest in Romania, where there are no public communications on this topic, so the Facebook content that I analyzed may reflect only a marginal category in the Romanian society. Furthermore, one of the assumptions that I make, based on my results, is that men are more likely to have pro-vaccine attitudes than women. I also assume gender predicts involvement in confrontational interactions regarding the HPV vaccine. Given the distrust towards the political system shown by the users in my study, I would expect political orientation to have no influence on HPV vaccination decisions.

The sample that I collected for my analysis comes only from one social media network, which could be a limitation of my research. However, Facebook is the most popular social 
media network in Romania and USA (Manafu, 2019; Statista - The Statistics Portal, 2019), so the content created here is relevant for these societies.

\section{References}

Allen, J. D., Othus, M. K. D., Shelton, R. C., Li, Y., Norman, N., Tom, L., \& del Carmen, M. G. (2010). Parental Decision Making about the HPV Vaccine. Cancer Epidemiology, Biomarkers \& Prevention, 19(9), 2187-2198.

Beck, U. (1992). Risk society: Towards a new modernity. London: Sage Publications.

Bruni, L., Albero, G., Serrano, B., Mena, M., Gómez, D., Muñoz, J., Bosch, F. X., \& De Sanjosé, S. (2018). Human Papillomavirus and Related Diseases in Romania. Summary Report. Barcelona.

Campbell, C. (1991). Reexamining Mills on Motive: A Character Vocabulary Approach. Sociological Analysis, 52(1), 89-97.

Centers for Disease Control and Prevention (2019) HPV-Associated Cancer Statistics, HPV and Cancer. Available at: https://www.cdc.gov/cancer/hpv/statistics/index.htm (Accessed: 10 December 2019).

Constantine, N. A., \& Jerman, P. (2007). Acceptance of Human Papillomavirus Vaccination among Californian Parents of Daughters: A Representative Statewide Analysis, Journal of Adolescent Health, 40(2), $108-115$.

Crăciun, C., \& Băban, A. (2012). "Who will take the blame?”: Understanding the reasons why Romanian mothers decline HPV vaccination for their daughters. Vaccine, 30, 6789-6793.

Dailard, C. (2006). The public health promise and potential pitfalls of the world's first cervical cancer vaccine. Guttmacher Policy Review, 9(1), 6-9.

Davis, K., Dickman, E. D., Ferris, D., \& Dias, J. K. (2004). Human papillomavirus vaccine acceptability among parents of 10- to 15-year-old adolescents. Journal of Lower Genital Tract Disease, 8(3), 188-194.

Dempsey, A. S., Zimet, G. D., Davis, R. L., \& Koutsky, L. (2006). Factors that are associated with parental acceptance of human papillomavirus vaccines: a randomized intervention study of written information about HPV. Pediatrics, 117(5). 1486-1493.

Difranzo, D. J., \& Gloria-Garcia, K. (2017). Filter bubbles and fake news. Crossroads, 23(3), 32-35.

Donovan, H., \& Bedford, H. (2013). Talking with parents about immunisation. Art \& science, 23(4), 16-20.

Dubé, E., Laberge, C., Guay, M., Bramadat, P., Roy, R., \& Bettinger, J. (2013). Vaccine hesitancy. Human Vaccines \& Immunotherapeutics, 9(8), 1763-1773.

Elo, S., \& Kyngäs, H. (2008). The qualitative content analysis. Journal of Advanced Nursing, 62(1), 107-115.

Fitzgerald, R. (2013). Motives in Social Organization. Journal of Comparative Research in Anthropology and Sociology, 4(2), 1-3.

Flaxman, S., Goel, S., \& Rao, J. M. (2016). Filter Bubbles, Echo Chambers, and Online News Consumption. Public Opinion Quarterly, 80, 298-320.

Gamble, H. L., Klosky, J. L., Parra, G. R., \& Randolph, M. E. (2010). Factors Influencing Familial Decision-Making Regarding Human Papillomavirus Vaccination. Journal of Pediatric Psychology, 35(7), 704-715.

Giddens, A. (1990). The Consequences of Modernity. Stanford: Polity Press.

Giddens, A. (1991). Modernity and self-identity: Self and Society in the Late Modern Age. Stanford: Stanford University Press.

Gilkey, M. B., Calo, W. A., Marciniak, M. W., \& Brewer, N. T. (2017). Parents who refuse or delay HPV vaccine: Differences in vaccination behavior, beliefs, and clinical communication preferences. Human Vaccines \& Immunotherapeutics, 13(3), 680-686.

Grandahl, M., Oscarsson, M., Stenhammar, C., Neveus, T., Westerling, R., \& Tyden, T. (2014). Not the right time: why parents refuse to let their daughters have the human papillomavirus vaccination. Acta Paediatrica, 103, 436-441.

Gross, G. J., \& Howard, M. (2001). Mothers' Decision-Making Processes Regarding Health Care for Their Children. Public Health Nursing, 18(3), 157-168. 
Hobson-West, P. (2007). "Trusting blindly can be the biggest risk of all”: organised resistance to childhood vaccination in the UK. Sociology of Health \& Illness, 29(2), 198-215.

Lenselink, C. H., Gerrits, M. M. J. G., Melchers, W. J. G., Massuger, L. F. A. G., van Hamont, D., \& Bekkers, R. L. M. (2008). Parental acceptance of Human Papillomavirus vaccines. European Journal of Obstetrics \& Gynecology and Reproductive Biology, 137(1), 103-107.

Institutul National de Sanatate Publica (2018). Ce ar trebui să ?tii despre infec? ia cu HPV ?i cancerul de col uterin? Available at https://www.insp.gov.ro/sites/INSP\%20documente/Brosura\%20MSD\%20Romana\%202.pdf

MacDonald, N. E. (2015). Vaccine hesitancy: Definition, scope and determinants. Vaccine, 14(33), 1-4.

Manafu, C. (2019) Social Media în România (2019). Available at: https://www.manafu.ro/2019/02/social-media-in-romania-2019/ (Accessed: 15 May 2019).

Mays, R. M., Sturm, L. A., \& Zimet, G. D. (2004). Parental perspectives on vaccinating children against sexually transmitted infections. Social Science \& Medicine, 58(7), 1405-1413.

Nguyen, C. T. (2018). Echo Chambers and Epistemic Bubbles. Episteme, 1-21.

Pariser, E. (2011). The Filter Buble What the Internet is Hiding from You. New York: The Penguin Press.

Pen?a, M., \& Băban, A. (2014). Dangerous Agent or Saviour? HPV Vaccine Representations on Online Discussion Forums in Romania. International Journal of Behavioral Medicine, 21(1), 20-28.

Perez, S., Shapiro, G. K., Brown, C. A., Dube, E., Ogilvie, G., \& Rosberger, Z. (2015). "I didn”t even know boys could get the vaccine': Parents' reasons for human papillomavirus (HPV) vaccination decision making for their sons. Psychooncology, 10, 1316-1323.

Petri, H. L., \& Cofer, C. N. (2018). Motivation. Encyclopcedia Britannica.

Poltorak, M., Leach, M., Fairhead, J., \& Cassell, J. (2005). "MMR talk" and vaccination choices: An ethnographic study in Brighton. Social Science \& Medicine, 61(3), 709-719.

Pop, C. A. (2016). Locating Purity within Corruption Rumors: Narratives of HPV Vaccination Refusal in a Peri-urban Community of Southern Romania. Medical Anthropology Quarterly, 30(4), p. n/a-n/a.

Rosenthal, S. L., Rupp, R., Zimet, G. D., Meza, H. M., Loza, M. L., Short, M. B., \& Succop, P. A. (2008). Uptake of HPV Vaccine: Demographics, Sexual History and Values, Parenting Style, and Vaccine Attitudes. Journal of Adolescent Health, 43(3), 239-245.

Rughini?, C., Ciocănel, A., \& Vasile, S. (2017). Homeopathy as Boundary Object and Distributed Therapeutic Agency. A Discussion on the Homeopathic Placebo Response. American Journal of Therapeutics, 25(4), 1-6.

Staras, S., Vadaparampil, S. T., Patel, R. P., \& Shenkman, E. A. (2014). Parent Perceptions Important for HPV Vaccine Initiation among Low Income Adolescent Girls. Vaccine, 32(46), 6163-6169.

Statista - The Statistics Portal (2019). Leading social media websites in the United States in May 2019, based on share of visits, Statista - The Statistics Portal.

Sturm, L. A., Mays, R. M., \& Zimet, G. D. (2005). Parental Beliefs and Decision Making About Child and Adolescent Immunization: From Polio to Sexually Transmitted Infections. Developmental and Behavioral Pediatrics, 26(6), 441-452.

Tangherlini, T. R., Roychowdhury, V., Glenn, B., Crespi, C. M., Bandari, R., Wadia, A., Falahi, M., Ebrahimzadeh, E., \& Bastani, R. (2016). "Mommy Blogs" and the Vaccination Exemption Narrative: Results From A Machine-Learning Approach for Story Aggregation on Parenting Social Media Sites. JMIR Public Health and Surveillance, 2(2), p. e166.

The Kaiser Family Foundation (2018). The HPV Vaccine: Access and Use in the U.S., The Kaiser Family Foundation. Available at: https://www.kff.org/womens-health-policy/fact-sheet/the-hpv-vaccine-accessand-use-in-the-u-s/ (Accessed: 10 December 2019).

Tiro, J. A., Meissner, H. I., Kobrin, S., \& Chollette, V. (2007). What do women in the U.S. know about human papillomavirus and cervical cancer? Cancer Epidemiology, Biomarkers \& Prevention, 16(2), 288-294.

Todorova, I., Alexandrova-Karamanova, A., \& Dimitrova, E. (2012). Doctors' and parents' perspectives on communication regarding HPV vaccination in Bulgaria.

Todorova, I., \& Băban, A. (2012). Contextual Constitution of Behavior: Introducing The HPV Vaccine in Easter Europe. 
Trim, K., Nagji, N., Elit, L., \& Roy, K. (2012). Parental Knowledge, Attitudes, and Behaviours towards Human Papillomavirus Vaccination for Their Children: A Systematic Review from 2001 to 2011. Obstetrics and Gynecology International, 1-12.

Del Vicario, M., Bessi, A., Zollo, F., Petroni, F., Scala, A., Caldarelli, G., Stanley, E., \& Quattrociocchi, W. (2016). The spreading of misinformation online. Proceedings of thr National Academy of Sciences, $554-559$.

Vlăsceanu, L., Duşa, A., \& Rughiniş, C. (2010). Publicul și știința. Știință și societate. Interese și percepții ale publicului privind cercetarea științifică și rezultatele cercetării. București.

Vulpe, S.-N., \& Stoian, M.-S. (2018). Vaccines: saving lives or depopulating the world? A discourse analysis. Journal of Comparative Research in Anthropology and Sociology - Compaso, 9(1), 67-87.

Wolfe, R. M., Sharp, L. K., \& Lipsky, M. S. (2002). Content and Design Attributes of Antivaccination Web Sites. Journal of the American Medical Association, 287(24), 3245-3248.

Wright Mills, C. (1940). Situated Actions and Vocabularies of Motive. American Sociological Review, 5(6), 904-913.

Zimet, G. D., Perkins, S. M., Sturm, L. A., Bair, R. M., Juliar, B. E., \& Mays, R. M. (2005). Predictors of STI vaccine acceptability among parents and their adolescent children. Journal of Adolescent Health, 37(3), 179-186.

Zimet, G. D., \& Rosenthal, S. L. (2010). HPV vaccine and males: Issues and challenges. Gynecologic Oncology, 117(2), S26-S31.

Zimmerman, R. Z., Wolfe, R. M., Fox, D. E., Fox, J. R., Nowalk, M. P., Troy, J. A., \& Sharp, L. K. (2005).Vaccine Criticism on the World Wide Web. Journal of Medical Internet Research, 7(2), p. e17.

Zuiderveen Borgesius, F. J., Trilling, D., Möller, J., Bodó, B., \& de Vreese, C. H. (2016). Should we worry about filter bubbles? Internet Policy Review Journal on internet regulation, 5(1), 1-16. 